\title{
HIGH EFFICIENCY MICROWAVE FLOW CHEMISTRY TOWARD SYNTHESIS OF FUNCTIONAL MATERIALS AND PHARMACEUTICAL CORES
}

Joshua P. Barham $^{1 *}$, Emiko Koyama ${ }^{1}$, Jun-ichi Sugiyama ${ }^{1}$, Yasuo Norikane ${ }^{1}$, Hiromichi Egami $^{2}$, Yoshitaka Hamashima ${ }^{2}$

${ }^{1}$ National Institute of Advanced Industrial Science and Technology, Tsukuba Central 5, 11-1 Higashi, Tsukuba, Ibaraki, 305-8565, Japan

${ }^{2}$ School of Pharmaceutical Sciences, University of Shizuoka, 52-1, Yada, Suruga-ku, Shizuoka, Shizuoka, 422-8526, Japan

*E-mail: j.barham@aist.go.jp; j.barham@saidagroup.jp

Keywords: microwave, flow, single-mode, radio-frequency heating, solid state microwave

Microwave (MW) heating benefits organic synthesis by affording higher product yields in shorter time periods than conventional heating $(\mathrm{CH})$, yet it suffers from poor scalability and is limited to polar solvents in typical batch mode reactors. ${ }^{1,2}$ An auto-frequency tunable microwave (AFT MW) continuous flow (CF) reactor has been developed and commercialized by SAIDA FDS Inc. and Pacific Microwave Technologies (PMT). ${ }^{3}$ ATF MW compensates for changes in the microwave absorption properties (permittivity, $\square$ ) with increasing temperature, ${ }^{1,2,4}$ affording excellent temperature and process control. Moreover, it is applicable to heating of non-polar solvents. Organic synthesis using an ATF MW CF reactor is a rapidly developing research field in Japan and beyond. ${ }^{5,6,7}$ Herein, we report recent applications of a microwave flow reactor using a solid-state semiconductor $\mathrm{MW}$ generator toward high efficiency synthesis of functional materials and pharmaceutical cores. Attention is drawn to examples where AFT MW heating has been compared to $\mathrm{CH}$ in flow, and where its application has expediated reaction optimization.

\section{CF synthesis comparing AFT MW heating with CH}

\subsection{Heterogeneous reactions}

Sajiki and co-workers at Gifu Pharmaceutical University disclosed a dehydrogenative aromatization under heterogeneous Pt catalysis using the AFT MW CF reactor (Fig. 1). ${ }^{8}$ When methylcyclohexane (MCH, $220 \mathrm{~mL})$ was passed through a straight-tube reactor filled with Pt catalyst mounted on carbon beads and heated by AFT MW (10 W applied power) at $0.5 \mathrm{~mL} / \mathrm{min}$ for $12 \mathrm{~h}$ of recirculation, $34 \mathrm{~L}$ of pure $\mathrm{H}_{2}$ gas was collected. This represented an energy-efficient method for $\mathrm{H}_{2}$ production, because the reflected MW power was only $1 \mathrm{~W}$ (90\% heating efficiency) with a catalyst TON of ca. 68,000 . The space-time yield of this system is ca. $1000 \mathrm{~mol} \mathrm{~L}_{\mathrm{cat}}^{-1} \mathrm{~h}^{-1}$, far superior to the rivalling organic chemical hydride (K$\mathrm{Pt} / \mathrm{Al}_{2} \mathrm{O}_{3}$-catalyzed) technology at $46 \mathrm{~mol} \mathrm{~L}_{\text {cat }}{ }^{-1} \mathrm{~h}^{-1} .{ }^{8}$ This process has great promises for $\mathrm{H}_{2}$ storage and transfer hydrogenation applications, because hydrogenation of aromatic rings (the reverse reaction) can be readily achieved under Pd catalysis. Therefore, it is an example of a functional material synthesis. The results of AFT MW heating (catalyst $\mathrm{T}=248^{\circ} \mathrm{C}$ ) vs. $\mathrm{CH}$ (oil bath $\mathrm{T}=248{ }^{\circ} \mathrm{C}$ ) were compared after $30 \mathrm{~min}$ of $\mathrm{CF}$. The former conditions gave ca. $2.0 \mathrm{~L}$ of $\mathrm{H}_{2}$ (ca. $25 \%$ yield) while the latter conditions gave ca. $0.2 \mathrm{~L}$ of $\mathrm{H}_{2}$ (ca. $2 \%$ yield). Thermography revealed that this is due to selective heating of the Carbon Bead support of the Pt catalyst by AFT MW, compared to unselective heating of the whole reactor by $\mathrm{CH}$. 

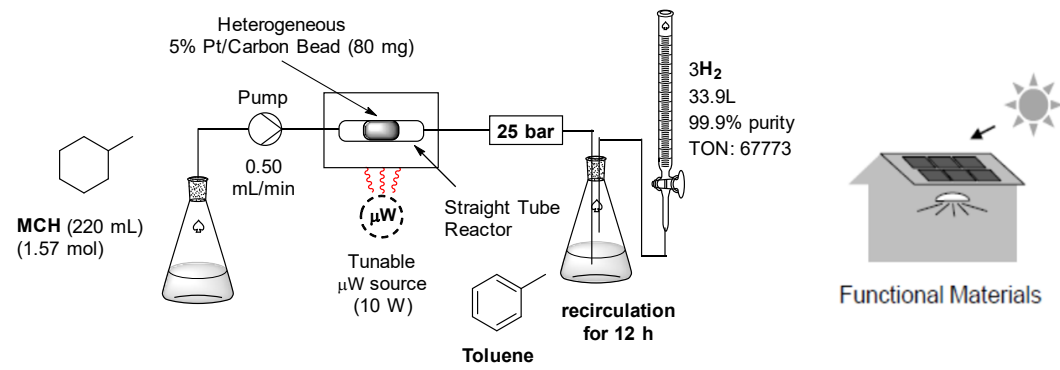

Fig. 1. Dehydrogenative aromatization of methylcyclohexane catalyzed by heterogeneous Pt/Carbon Bead disclosed by Sajiki and co-workers. ${ }^{8}$
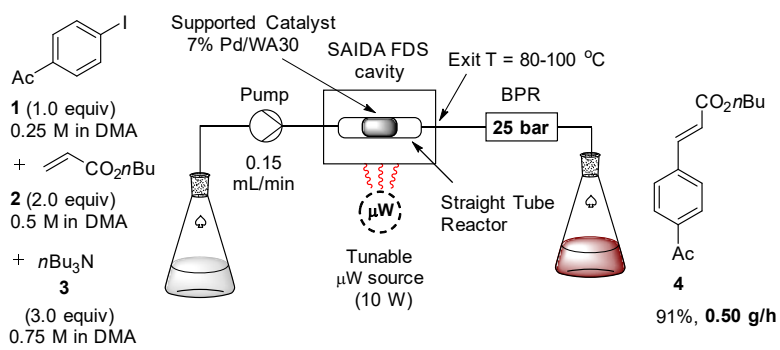

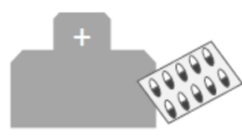

Pharmaceuticals

Fig. 2. MW CF Heck reaction under heterogeneous Pd-supported catalysis.

Sajiki and co-workers reported a heterogeneous Mizuroki-Heck reaction using supported Pd catalysis in a straight tube within the AFT MW CF reactor. ${ }^{9}$ In one example, product 4 was afforded in up to $91 \%$ yield, $0.5 \mathrm{~g} / \mathrm{h}$. When the aryl iodide substrate 1 was changed, different exit temperatures were observed under the same applied MW power. This observation implicated the selective MW heating of reagents in the presence of solvent. Accordingly, a slight improvement in yield was observed when the reaction was performed using AFT MW heating $(92 \% 4,4 \% 1)$ vs. $\mathrm{CH}(87 \% 4,8 \% 1)$ under the same $\mathrm{CF}$ conditions. ${ }^{9}$ The MizorokiHeck reaction furnishes multi-substituted alkenes as ubiquitous intermediates in organic chemistry and in the pharmaceutical industry. ${ }^{10}$

\subsection{Homogeneous reactions}

At AIST, we applied AFT MW heating to the CF synthesis of $\mathrm{IC}_{60} \mathrm{MA}$ and $\mathrm{IC}_{60} \mathrm{BA}$ via a mismatched (electron-rich + electron-rich) Diels-Alder-type conjugation reaction between $\mathrm{C}_{60}$ and indene. ${ }^{5}$ The synergy of AFT MW heating and $\mathrm{CF}$ was realized in the ability to synthesize $\mathrm{IC}_{60} \mathrm{MA}$ and $\mathrm{IC}_{60} \mathrm{BA}$ in productivities as high as $0.7 \mathrm{~g} / \mathrm{h}(47 \%$ yield $)$ and $0.5 \mathrm{~g} / \mathrm{h}$ ( $32 \%$ yield), respectively. This is important because $\mathrm{IC}_{60} \mathrm{MA}$ and $\mathrm{IC}_{60} \mathrm{BA}$ have been demonstrated as superior electron acceptors with enhanced solubility vs. phenyl-C61-butyric acid methyl ester (PCBM) as the benchmark electron acceptor in polymer solar cells. ${ }^{11}$ Moreover, non-polar solvent $o$-xylene could be heated to $270^{\circ} \mathrm{C}$ which is next to impossible in other (non-AFT) MW reactors. The use of $o$-xylene in place of high-boiling polychlorinated aromatic solvents improves the cost-efficiency and green chemistry of these reactions. ${ }^{5}$ At room temperature, the MW absorption property, $\tan \square$, of the reaction mixture (o-Xylene + indene $+\mathrm{C}_{60}$ ) was very similar to that of the solvent only (o-Xylene) (Table 1$)$, indicating there should be no selective reagent heating. Indeed, under the same conditions of $\mathrm{R}_{\mathrm{T}}$ and exit temperature, the CF reaction gave very similar results for AFT MW heating 
vs. $\mathrm{CH}$ (Table 2). Here, the $\mathrm{CH}$ reactor was a ceramic furnace fitted with thermocouples (Fig. 4, left). External thermocouples 1-4 are fitted to the reactor tube surface and external thermocouple 5 is fitted to the inner furnace wall. 'Saida' is the internal thermocouple measuring the exit temperature of the flowing solution inside; its readings corresponded well with thermocouple 1 (Fig. 4, right). External thermocouple 6 (not shown) is fitted to the end of the cooling loop prior to the BPR.



Fig. 3. Top: $\mathrm{C}_{60} /$ indene conjugation reaction scheme with structures of $\mathrm{IC}_{60} \mathrm{MA}$ and $\mathrm{IC}_{60} \mathrm{BA}$. Bottom: MW $\mathrm{CF} \mathrm{C}_{60}$ /indene conjugation reaction.

Table 1. Permittivity Data for $\mathrm{C}_{60} /$ indene conjugation reaction components

\begin{tabular}{cccc}
\hline Entry & Sample & $\begin{array}{c}\square{ }^{\prime}-\mathrm{j} \square{ }_{\mathrm{r}}{ }^{\prime \prime}(2.45 \\
\mathrm{GHz})\end{array}$ & $\tan \square$ \\
\hline 1 & $o$-Xylene & $2.70-\mathrm{j} 0.08$ & 0.030 \\
2 & $o$-Xylene $+\mathrm{C}_{60}$ & $2.72-\mathrm{j} 0.09$ & 0.033 \\
3 & $o-X y l e n e+$ indene & $2.84-\mathrm{j} 0.11$ & 0.038 \\
4 & $o$-Xylene $+\mathrm{C}_{60}+$ indene & $2.84-\mathrm{j} 0.11$ & 0.039 \\
\hline
\end{tabular}

All samples were recorded at $\mathrm{rt}$ at $2.45 \mathrm{GHz} . \mathrm{H}_{2} \mathrm{O}$ was employed as a standard.

Table 2. Effect of AFT MW heating vs. $\mathrm{CH}$ on yields of $\mathrm{IC}_{60} \mathrm{MA}$ and $\mathrm{IC}_{60} \mathrm{BA}$ from the $\mathrm{CF}$ reaction of $\mathrm{C}_{60}$ and indene.

\begin{tabular}{cccccc}
\hline Entry & $\mathrm{T}^{\mathrm{a}}\left({ }^{\circ} \mathrm{C}\right)$ & Heating Type & \multicolumn{3}{c}{ Yields $^{\mathrm{b}}$} \\
\cline { 4 - 6 } & & & $\mathrm{C}_{60}$ & $\mathrm{IC}_{60} \mathrm{MA}$ & $\mathrm{IC}_{60} \mathrm{BA}$ \\
\hline 1 & 260 & $220 \mathrm{~W} \mathrm{MW}$ & 26 & 46 & 11 \\
2 & 260 & N/A $(\mathrm{CH})$ & 25 & $41[42]$ & 9 \\
3 & 270 & $220 \mathrm{~W} \mathrm{MW}$ & 20 & 47 & 15 \\
4 & 270 & N/A $(\mathrm{CH})$ & 21 & $46[46]$ & 12 \\
\hline
\end{tabular}

$\mathrm{T}=$ temperature. $\mathrm{R}_{\mathrm{T}}=$ residence time. All reactions used a $0.90 \min \mathrm{R}_{\mathrm{T}}, 5.4 \mathrm{mM} \mathrm{C} 60,1.6 \mathrm{M}$

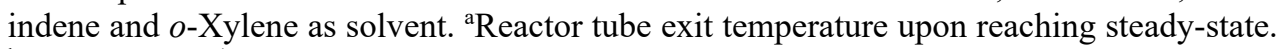
${ }^{\mathrm{b}} \mathrm{HPLC}$ yields. ${ }^{1} \mathrm{H}$ NMR yields in parenthesis. 
Amides are one of the most important moeities in organic chemistry and in pharmaceuticals, but amide bond formations typically require inefficient or hazardous coupling reagents. ${ }^{12}$ Novel methods for construction of functionalization of amides are desirable to researchers and industry. At the University of Shizuoka, we applied AFT MW CF reactor to a basecatalyzed C-alkylation reaction of NMP with styrene (Fig. 5). ${ }^{13}$ AFT MW heating in CF allowed $180^{\circ} \mathrm{C}$ to be achieved at $\mathrm{R}_{\mathrm{T}}=0.4 \mathrm{~min}$ for a given reaction mixture $(0.44 \mathrm{M}$ styrene, $0.26 \mathrm{M} \mathrm{NaO} t \mathrm{Bu}$ and $0.26 \mathrm{M} 18$-crown-6 in NMP), resulting in a productivity of $65 \mathrm{~g} / \mathrm{h}$ as an upper limit. At lower $\mathrm{R}_{\mathrm{T}}$, the maximum applied MW power $(200 \mathrm{~W})$ is insufficient to reach $180{ }^{\circ} \mathrm{C}$. The MW absorption property $\tan \square$ of the reaction mixture (NMP $+\mathrm{NaO} t \mathrm{Bu}$ +18 -crown-6 + styrene) vs. solvent only (NMP) were very

similar at room temperature (Table 3 ), indicating there should be no selective reagent heating. In this case, however, under the same conditions of $\mathrm{R}_{\mathrm{T}}$ and exit temperature, the reaction gave superior results for the AFT MW heating vs. $\mathrm{CH}$ in $\mathrm{CF}$ (Table 4).
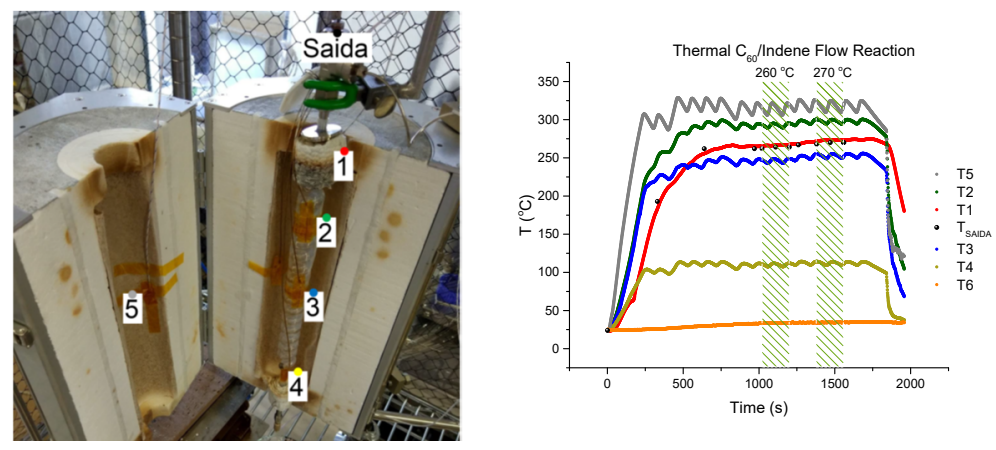

Fig. 4. Left: Ceramic furnace reactor fitted with external thermocouples 1-5 and internal thermocouple 'Saida'. Right: Temperature data for $\mathrm{CH}$ experiments in Table 2.

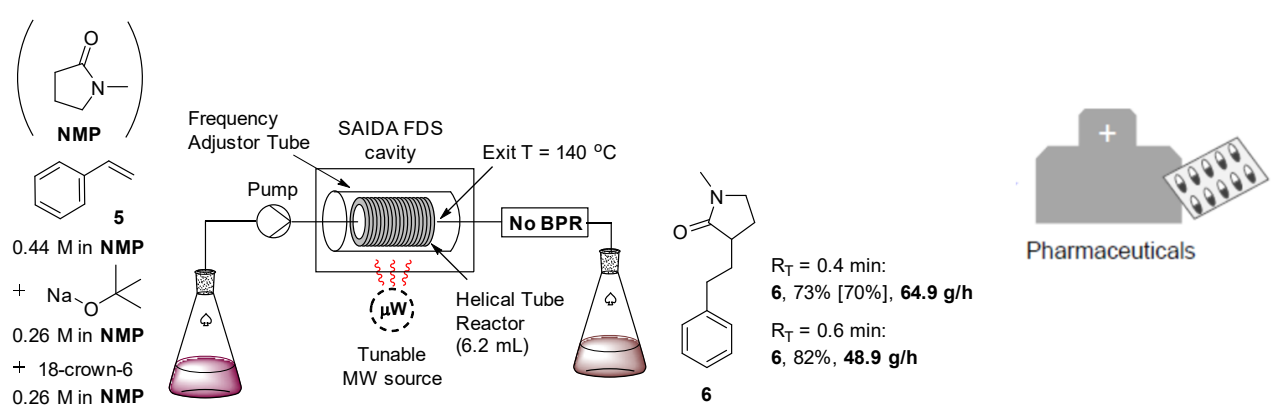

Fig. 5. Top: $\mathrm{C}_{60} /$ indene conjugation reaction scheme with structures of $\mathrm{IC}_{60} \mathrm{MA}$ and IC 60 BA. Bottom: MW CF $\mathrm{C}_{60} /$ indene conjugation reaction. 
Table 3. MW CF base-catalyzed C-alkylation reaction of NMP with styrene.

\begin{tabular}{cccc}
\hline Entry & Sample & $\begin{array}{c}\square{ }^{\prime}-\mathrm{j} \square \mathrm{r} \text { ' }(2.45 \\
\mathrm{GHz})\end{array}$ & $\tan \square$ \\
\hline 1 & $\mathrm{NMP}$ & $14.15-\mathrm{j} 12.56$ & 0.888 \\
2 & $\mathrm{NMP}+\mathrm{NaO} t \mathrm{Bu}$ & $13.56-\mathrm{j} 11.42$ & 0.842 \\
3 & $\mathrm{NMP}+\mathrm{NaO} t \mathrm{Bu}+18$-crown-6 & $11.60-\mathrm{j} 9.72$ & 0.838 \\
4 & $\mathrm{NMP}+\mathrm{NaO} t \mathrm{Bu}+18$-crown-6 + styrene & $12.08-\mathrm{j} 9.92$ & 0.821 \\
5 & $\mathrm{NMP}+18$-crown-6 & $12.89-\mathrm{j} 11.29$ & 0.876 \\
6 & $\mathrm{NMP}+$ styrene & $13.49-\mathrm{j} 11.37$ & 0.843 \\
7 & $\mathrm{NMP}+\mathrm{NaO} t$ Bu + styrene & $12.36-\mathrm{j} 10.48$ & 0.848 \\
8 & $\mathrm{NMP}+18$-crown-6 + styrene & $13.15-\mathrm{j} 10.79$ & 0.821 \\
\hline
\end{tabular}

All samples were recorded at $\mathrm{rt}$ at $2.45 \mathrm{GHz} . \mathrm{H}_{2} \mathrm{O}$ was employed as a standard.

In the case of MW, thermography was used to measure the reactor surface temperature gradient from bottom to top of the reactor tube (locations 1-16, Fig. 5, left, center) with calibration as previously described. ${ }^{6}$ The surface temperature increased in a non-linear fashion and the surface temperature of locations near the reactor exit were in agreement with the internal exit temperature (Fig. 5, right). Together with the dielectric constant of the Duran pipe $\left(\square \mathrm{r}^{\prime}=4.6,1 \mathrm{MHz}, 25^{\circ} \mathrm{C}\right)^{6}$ being much lower than $\mathbf{N M P}\left(\square{ }_{\mathrm{r}}{ }^{\prime}=14.2,2.45 \mathrm{GHz}, 25^{\circ} \mathrm{C}\right)$, this indicates the surface temperature is similar to the internal temperature and confirms the direct nature of radiative heating of the reaction mixture by $\mathrm{MW}$. $\mathrm{CH}$ requires much higher surface temperatures (locations 5,15, Fig. 5, right) to deliver the same internal exit temperature. The high concentration and high-polarity solvent (NMP) yields more effective heat transfer by MW to the fast-flowing reaction mixture over the same given residence time than that of $\mathrm{CH}$. This 'thermal' $\mathrm{MW}$ effect is less pronounced for the $\mathrm{C}_{60}$ /indene conjugation reaction, where heating of the Duran reactor tube and $o$-Xylene occurs in competition (such an effect has been previously reported for Duran and CPME). ${ }^{6}$ Dielectric properties may change at elevated temperatures, so a 'non-thermal' microwave effect cannot be exclusively ruled out.

Table 4. Effect of AFT MW heating vs. thermal heating on yields of monoadduct 6 from the $\mathrm{CF}$ base-catalyzed $\mathrm{C}$-alkylation reaction of NMP with styrene.

\begin{tabular}{cccc}
\hline Entry & $\mathrm{T}^{\mathrm{a}}\left({ }^{\circ} \mathrm{C}\right)$ & MW power $(\mathrm{W})$ & ${\text { Yield } \mathbf{6}^{\mathrm{b}}}^{\mathrm{b}}$ \\
& & & \\
\hline 1 & 140 & $0-200^{\mathrm{c}}$ & $30^{\mathrm{d}}$ \\
2 & 140 & N/A (thermal) & $14^{\mathrm{e}}$ \\
\hline
\end{tabular}

$\mathrm{T}=$ temperature. $\mathrm{R}_{\mathrm{T}}=$ residence time. All reactions used a $0.55 \mathrm{~min} \mathrm{R}_{\mathrm{T}}, 0.44 \mathrm{mM}$ styrene,

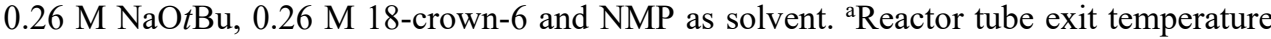
upon reaching steady-state. ${ }^{\mathrm{b}} \mathrm{NMR}$ yields. ${ }^{\mathrm{c}} \mathrm{A}$ temperature control algorithm was employed which varied the applied MW power until desired steady-state temperature was reached. ${ }^{\mathrm{d}}$ Average of 2 replicates. ${ }^{\mathrm{e}}$ Average of 3 replicates. 

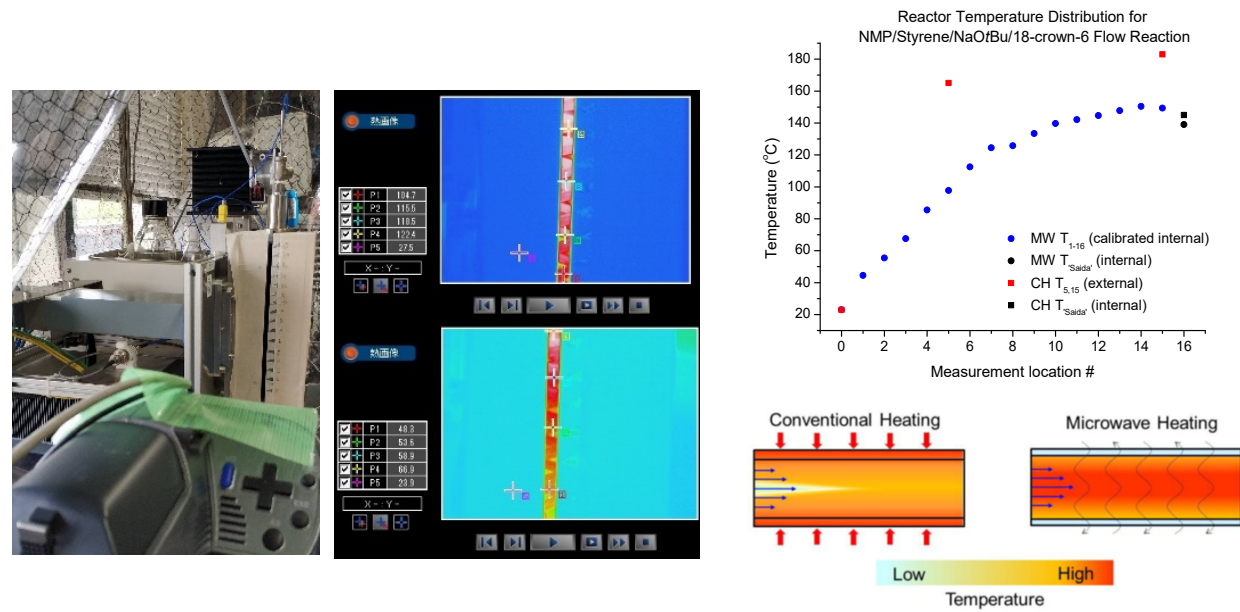

Fig. 5. Left: Thermography apparatus showing measurement locations $1-16$. Location 0 at the assumed to be $\mathrm{rt}\left(23^{\circ} \mathrm{C}\right)$. Center: Thermography picture and data (uncalibrated, locations 1,3,5,7 and 8,10,12,14 are shown from bottom to top). Right: Reactor temperature distribution for $\mathrm{NMP} / \mathrm{Styrene} / \mathrm{NaO} t \mathrm{Bu} / 18$-crown- $6 \mathrm{CF}$ reaction and illustration of inverted thermal gradient for MW $\mathrm{CF}$ vs. $\mathrm{CH} \mathrm{CF}{ }^{7}$

\section{Applications of AFT MW heating toward rapid optimization studies}

Mase and co-workers at Shizuoka University reported a kilo-scale alcohol acetylation using the AFT MW CF reactor (up to ca. $9.0 \mathrm{~kg}$ /day of ester 9, Fig. 6) ${ }^{14}$ In order to achieve the optimal conditions, they fitted the MW CF reactor with a flowIR cell, monitored the yield in-line and fed the data to a 9+4+1 optimization method (Fig. 7). They identified the upper and lower limits of MW applied power and flow rate as variables and yield as the response. They divided the range of each variables by 3 to arrive at 9 experimental runs (black spots). The point which gave the best yield was divided into four and four further experiments performed (grey spots). A final experiment was performed according to the expected optimum condition (white spot). In DoE analysis, factorial designs are generally more efficient and reliable compared to OFAT methods or the $9+4+1$ method. ${ }^{15}$ At AIST, we utilized a two-factorial face-centred central composite design (CCD) for the optimization of the $\mathrm{C}_{60}$ /indene conjugation (Fig. 8). ${ }^{5}$ The 8 experiments for the cube design combined with the 6 experiments for the star design and several $(5 \mathrm{x})$ central points were used to build the $\mathrm{CCD}$, which imparted a deep understanding of the relative importance of temperature, [indene] and $\mathrm{R}_{\mathrm{T}}$ on the $\mathrm{C}_{60}$ conversion ( $\mathrm{R}_{\mathrm{T}}$ was most important).

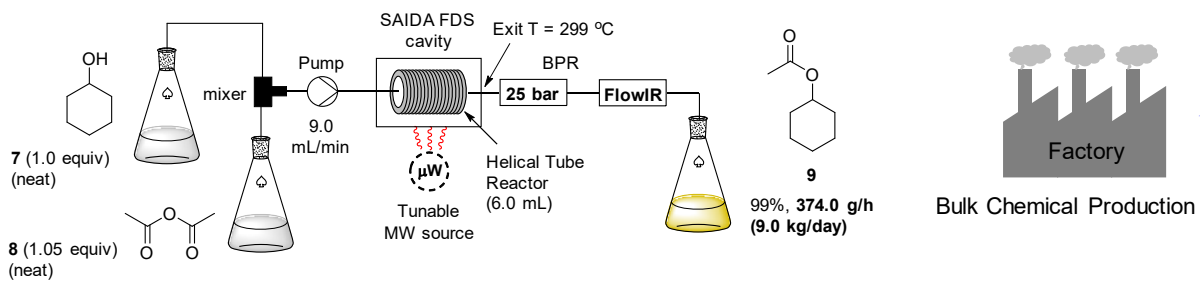

Fig. 6. MW CF acetylation of cyclohexanol with acetic anhydride. 


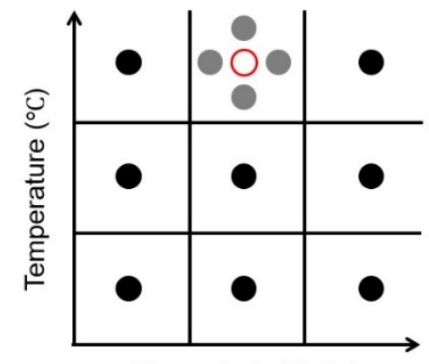

Flow rate $(\mathrm{mL} / \mathrm{min})$

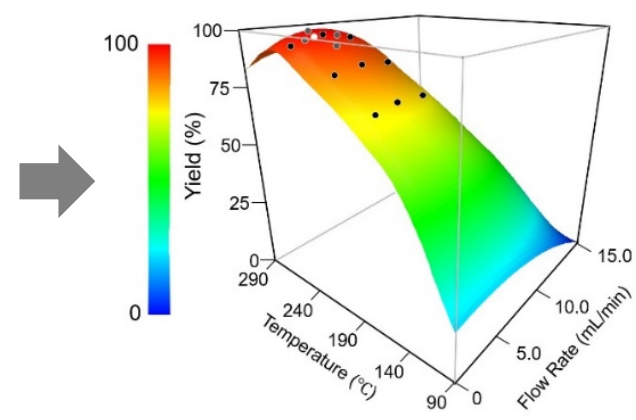

Fig. 7. 9+4+1 OFAT method construction and application to an alcohol acetylation reaction. Note: data differs from the reported study and is shown for illustration.


Fig. 8. Top: Construction of a two-factorial face-centred central composite design (CCD) from a two-level full factorial cubic design and a face-centred star design. Bottom (left): Illustrative application. Bottom (right): Application to $\mathrm{C}_{60} /$ indene conjugation reaction.

The solid state oscillator's ability to continuously detect and match the temperaturedependent microwave absorption resonant frequency allowed rapid and controlled changes in $\mathrm{T}$ which culminated in rapid data acquisition (on average, $<5 \mathrm{~min}$ intervals between runs of different temperatures). In contrast to OFAT methods, the factorial nature of the CCD allows it to reveal multifactor interactions, although such interactions were not significant in the $\mathrm{C}_{60}$ /indene conjugation reaction. The successful construction of the $\mathrm{CCD}$ requires the results of reactions under 'extreme' conditions at the edges of the design space and is in itself a testament to the robustness of AFT MW CF technology. Elsewhere, AFT-MW CF technology has been leveraged for the OFAT-type optimization of a Johnson-Claisen rearrangement ${ }^{16}$ and the synergy of AFT MW CF with software programs that automatically vary the flow rate and MW power has been employed to rapidly optimize an ortho-Claisen rearrangement reaction of allyl 1-napthyl ether. ${ }^{6}$ 


\section{Summary}

AFT MW applicators allow better temperature control and energy efficiency to CF reactions than other (non-AFT) MW applicators and they can successfully heat non-polar solvents such as $o$-Xylene and CPME. The reaction temperature can be rapidly changed which expediates reaction optimization and allows conservation of reaction mixture. The combination of AFT MW heating and CF has enabled high efficiency synthesis of functional materials and pharmaceutical cores.

\section{Acknowledgements}

The authors gratefully acknowledge the technical support from the National Institute of Advanced Industrial Science and Technology and the University of Shizuoka, as well as financial support from NEDO, Shizuoka Prefectural Government. Joshua P. Barham is grateful for financial support from JSPS (KAKENHI Grant Number JP18F19030). The authors are grateful for Shizuoka University (Prof. Noboyuki Mase's group) and Gifu Pharmaceutical University (Prof. Hironao Sajiki's group) for their research in this area.

\section{References}

1. Stuerga, D. in Microwaves in Organic Synthesis, $2^{\text {nd }}$ Ed., Wiley-VCH, 2006, pp 929.

2. Grant, E., Halstead, B. J. Chem. Soc. Rev. 1998, 27, 213-224.

3. a) Saida, H., Odajima, H., Ohneda, S., Yokozawa, S. (SAIDA FDS Inc.) 2012, WO/2012/043753; b) saidagroup.jp/fds; c) pacificmicrowave.com

4. Chandrasekaran, S., Ramanathan, S., Basak, T. AIChE J. 2012, 58, 330-363.

5. Barham, J. P., Tanaka, S., Koyama, E., Ohneda, N., Okamoto, T., Odajima, H., Sugiyama, J., Norikane, Y. J. Org. Chem., 2018, 83, 4348-4354.

6. Koyama, E., Ito, N., Sugiyama, J., Barham, J. P., Norikane, Y., Azumi, R., Ohneda, N., Ohno, Y., Yoshimura, T., Odajima, H., Okamoto, T. J. Flow Chem., 2018, 8, 147-156.

7. Barham, J. P., Koyama, E., Norikane, Y., Ohneda, N., Yoshimura, T. Chem. Rec., 2019, 19, 188-203.

8. Ichikawa, T., Matsuo, T., Tachikawa, T., Yamada, T., Yoshimura, T., Yoshimura, M., Takagi, Y., Sawama, Y., Sugiyama, J., Monguchi, Y., Sajiki, H. ACS Sustainable Chem. Eng. 2019, 7, 3052-3061.

9. Ichikawa, T., Mizuno, M., Ueda, S., Ohneda, N., Odajima, H., Sawama, Y., Monguchi, Y., Sajiki, H. Tetrahedron Lett. 2018, 74, 1801-1816.

10. Budarin, V. L., Shuttleworth, P. S., Clark, J. H., Luque, R. Curr. Org. Synth. 2010 , 7, 614-627.

11. He, Y., Chen, H.-Y., Hou, J., Li, Y., J. Am. Chem. Soc. 2010, 132, 1377-1382.

12. Sabatini, M. T., Boulton, L. T., Sheppard, T. D. Sci. Adv. 2017, 3, e1701028.

13. Barham, J. P., Tamaoki, S., Egami, H., Ohneda, N., Okamoto, T., Odajima, H., Hamashima, Y. Org. Biomol. Chem., 2018, 16, 7568-7573.

14. Vámosi, P., Matsuo, K., Masuda, T., Sato, K., Narumi, T., Takeda, K., Mase, N. Chem. Rec., 2019, 19, 77-84.

15. Weissman, S. A., Anderson, N. G. Org. Process Res. Dev. 2015, 19, 1605-1633.

16. Egami, H., Tamaoki, S., Abe, M., Ohneda, N., Yoshimura, T., Okamoto, T., Odajima, H., Mase, N., Takeda, K., Hamashima, Y. Org. Process Res. Dev. 2018, 22, 1605-1633. 


\section{About the authors}
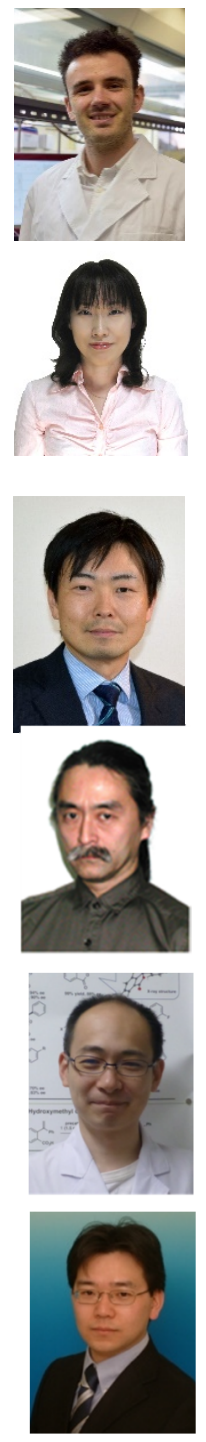

Joshua P. Barham, JSPS Research Fellow at AIST: Expert in photochemical and microwave flow chemistry in organic synthesis. Ph.D in Chemistry from the University of Strathclyde/GlaxoSmithKline Collaborative Ph.D Programme. Previously with SAIDA FDS Inc./University of Shizuoka as a NEDO Japan Trust Research Fellow.

Emiko Koyama, Researcher at AIST: Expert in microwave flow chemistry in organic synthesis. Ph.D in Engineering from Tokyo Institute of Technology. Previously with University of Tsukuba as an Assistant Professor.

Yasuo Norikane, Group Leader at AIST and Associate Professor at the University of Tsukuba: Expert in photochemistry in organic synthesis. Ph.D in Science from the University of Tsukuba. Previously with Scripps as a Postdoctoral Research Fellow.

Jun-ichi Sugiyama, Researcher at AIST: Expert in microwave heating theory and chemistry. Ph.D in Engineering from Tokyo Institute of Technology. Previously with Yamagata University as an Assistant Professor.

Hiromichi Egami, Associate Professor at University of Shizuoka: Expert in microwave flow chemistry in organic synthesis. Ph.D in Science from Kyushu University. Previously with the ERATO Sodeoka Live Cell Chemistry Project as a Postdoctoral Research Fellow and Group Leader.

Yoshitaka Hamashima, Full Professor at University of Shizuoka: Expert in microwave flow chemistry in organic synthesis. Ph.D in Pharmacy from the University of Tokyo. Previously with Tohoku University as an Assistant Professor and RIKEN as a Senior Researcher. 